\title{
Isolation and kinetic characterisation of hydrophobically distinct populations of form I Rubisco
}

Kerry O'Donnelly ${ }^{1}$, Guangyuan Zhao ${ }^{2}$, Priya Patel ${ }^{2}$, M Salman Butt ${ }^{1}$, Lok Hang Mak², Simon Kretschmer², Rudiger Woscholski ${ }^{1}$ and Laura M C Barter ${ }^{r^{*}}$

\begin{abstract}
Background: Rubisco (Ribulose-1,5-bisphosphate carboxylase/oxygenase) is a Calvin Cycle enzyme involved in $\mathrm{CO}_{2}$ assimilation. It is thought to be a major cause of photosynthetic inefficiency, suffering from both a slow catalytic rate and lack of specificity due to a competing reaction with oxygen. Revealing and understanding the engineering rules that dictate Rubisco's activity could have a significant impact on photosynthetic efficiency and crop yield.

Results: This paper describes the purification and characterisation of a number of hydrophobically distinct populations of Rubisco from both Spinacia oleracea and Brassica oleracea extracts. The populations were obtained using a novel and rapid purification protocol that employs hydrophobic interaction chromatography (HIC) as a form I Rubisco enrichment procedure, resulting in distinct Rubisco populations of expected enzymatic activities, high purities and integrity.

Conclusions: We demonstrate here that HIC can be employed to isolate form I Rubisco with purities and activities comparable to those obtained via ion exchange chromatography (IEC). Interestingly, and in contrast to other published purification methods, HIC resulted in the isolation of a number of hydrophobically distinct Rubisco populations. Our findings reveal a so far unaccounted diversity in the hydrophobic properties within form 1 Rubisco. By employing HIC to isolate and characterise Spinacia oleracea and Brassica oleracea, we show that the presence of these distinct Rubisco populations is not species specific, and we report for the first time the kinetic properties of Rubisco from Brassica oleracea extracts. These observations may aid future studies concerning Rubisco's structural and functional properties.
\end{abstract}

Keyword: Brassica oleracea, Hydrophobic interaction chromatography, Purification, Rubisco, Spinacia oleracea

\section{Background}

Rubisco (Ribulose-1,5-bisphosphate carboxylase/oxygenase) is the $\mathrm{CO}_{2}$-fixing enzyme in the Calvin cycle, the primary pathway of carbon assimilation in photosynthetic organisms. It catalyses the reaction between Ribulose-1,5-bisphosphate ( $\mathrm{RuBP})$ and $\mathrm{CO}_{2}$ to produce two molecules of 3-phosphoglycerate [1,2]. It is reported that Rubisco is responsible for a net fixation of $10^{11}$ tons of $\mathrm{CO}_{2}$ from the atmosphere to the biosphere per year [3]. Despite its importance, Rubisco is a remarkably

\footnotetext{
* Correspondence: I.barter@imperial.ac.uk

'Institute of Chemical Biology, Department of Chemistry, Imperial College, Flowers Building, South Kensington Campus, Exhibition Road, London SW7 $2 A Z, U K$

Full list of author information is available at the end of the article
}

inefficient enzyme, suffering from both poor specificity and a slow catalytic rate. It is not surprising that this enzyme has generated much interest, as it is suggested to be one of the major bottlenecks limiting maximum photosynthetic efficiency [4]. The efficiency of carbon fixation is reduced by side reactions, the most notable being photorespiration, where Rubisco fixates $\mathrm{O}_{2}$ instead of $\mathrm{CO}_{2}$. Photorespiration imposes a significant metabolic constraint, lowering the efficiency of carbon fixation by up to $25-50 \%$ and constantly draining the pool of available RuBP [5,6]. Rubisco is the most abundant protein found on the planet, making up approximately $50 \%$ of the total leaf protein [7]. This however comes at a cost in terms of the plant's nitrogen requirements [1]. 
Rubisco is a multimeric enzyme comprising varying numbers of the large $(50-55 \mathrm{kDa})$ and small subunits $(12-18 \mathrm{kDa})$, which in higher plants and green algae are encoded by the chloroplast genome and the nuclear genome respectively $[2,8]$. There are a number of different forms of Rubisco (forms I, II and III, as well as the more diverse Rubisco-like proteins (RLPs) called form IV), reviewed by Tabita et al. [9]. Form I Rubisco is the most common, found in higher plants, cyanobacteria and eukaryotic algae [2], and its structure has been solved in many species, but first reports were for tobacco [10] and spinach [11]. It consists of eight large and eight small subunits in a hexadecameric structure, forming a barrel of four large subunit dimers arranged around a four-fold axis of symmetry, capped by four small subunits at each end $[8,12]$. The large subunits play a catalytic role, however the precise role of the small subunit is not clear, as it is not essential for catalysis $[13,14]$. Interestingly hybrid enzymes which contain large subunits and small subunits from different species have been reported to show differences in their stability and specificity [15-17].

There is a lack of understanding of the interactions and engineering rules that control and regulate Rubisco's activity, although this is critical if we are to increase photosynthetic efficiency. A prerequisite for the characterisation of the structure and function of Rubisco, along with investigations into its interactome, is the need for rapid methods that can isolate Rubisco with high purity. Purification methods in the past have taken advantage of the enzyme's negative net charge under physiological $\mathrm{pH}$, which make it suitable for anion exchange chromatography [18-21], as well as the relatively high molecular weight of the hexadecameric holoenzyme, which made it an ideal candidate for size exclusion chromatography, or sucrose gradient centrifugation [22-25]. In addition, differential ammonium sulphate $\left(\left(\mathrm{NH}_{4}\right)_{2} \mathrm{SO}_{4}\right)$ precipitation has been employed prior to the ion exchange chromatography (IEC) [19,24]. A number of the reported high purity Rubisco isolation protocols are lengthy, due to the need for dialysis or ultra-centrifugation to remove sucrose prior to assaying the sample, which leads to an increased risk of endoproteolytic activity on the homogenized leaf tissue [26]. Given the wide use and effectiveness of $\left(\mathrm{NH}_{4}\right)_{2} \mathrm{SO}_{4}$ precipitation it is surprising that hydrophobic interaction chromatography (HIC), which is based on similar separation principles, has only been explored once as a purification technique for form III Rubisco from recombinant $A$. fulgidu, but has yet to be employed for form I Rubisco [27].

The potential of HIC as an alternative to IEC to obtain form I Rubisco with high purity was explored, since it is ideally suited as the proceeding step to the commonly employed $\left(\mathrm{NH}_{4}\right)_{2} \mathrm{SO}_{4}$ precipitation in Rubisco purification protocols [28]. Employing $\left(\mathrm{NH}_{4}\right)_{2} \mathrm{SO}_{4}$ in purification protocols may have the added benefit of removing endogenous inhibitors, since the presence of sulphate ions in Rubisco extraction buffers has been shown to remove and prevent the binding of inhibitors such as 2 carboxyD-arabinitol 1-phosphate (CA1P) [29,30]. $\left(\mathrm{NH}_{4}\right)_{2} \mathrm{SO}_{4}$ precipitation results in samples with high salt content, which require dialysis, desalting or dilution prior to the subsequent IEC purification step. In contrast, HIC can exploit the high salt content of the $\left(\mathrm{NH}_{4}\right)_{2} \mathrm{SO}_{4}$ precipitate, therefore avoiding any further dilution or desalting steps. HIC, like IEC, offers the added advantage of being able to bind proteins from large sample volumes, which is in contrast to gel filtration chromatography and sucrose gradient centrifugation, often employed in addition to IEC $[19,24]$.

We demonstrate here a rapid purification method that, for the first time, is able to reveal hydrophobically distinct Rubisco populations. Our results confirm that the HIC protocol, detailed here, can be employed to obtain highly purified Rubisco from Spinacia oleracea (S. oleracea, Spinach), with kinetic properties in agreement with literature values from samples subjected to commonly employed purification protocols [20,31].

Once verified by this comparison, the HIC method was utilised to purify Rubisco from another species, the so far uncharacterised enzyme from Brassica oleracea (B. oleracea, Cabbage), revealing for the first time the kinetic properties of Rubisco from this species.

\section{Results and discussion}

In order to test the suitability of HIC, lysed samples from both $S$. oleracea and $B$. oleracea were subjected to $\left(\mathrm{NH}_{4}\right)_{2} \mathrm{SO}_{4}$ precipitation, with the majority of Rubisco protein precipitating between 35 and $60 \%$ saturation of $\left(\mathrm{NH}_{4}\right)_{2} \mathrm{SO}_{4}$ (Figure 1). As expected, this observation is in agreement with previous reports where $\left(\mathrm{NH}_{4}\right)_{2} \mathrm{SO}_{4}$ precipitation has been employed to extract Rubisco from higher plant species, including $S$. oleracea and Arabidopsis [24,32].

\section{HIC reveals the presence of hydrophobically distinct Rubisco fractions}

As the HIC column binds proteins at high salt concentration, the $\left(\mathrm{NH}_{4}\right)_{2} \mathrm{SO}_{4}$ fraction containing Rubisco was directly subjected to our HIC protocol (without the need to desalt the sample). Our method is summarised in Figure 2, which also shows a typical Rubisco isolation and purification protocol taken from Salvucci et al. for comparison [24]. Bound proteins were step-eluted in order to gain reproducibility, while conserving simplicity in handling (facilitating the potential use of syringe operated columns). A typical UV trace of the HIC elution profile demonstrates that a substantial proportion of the loaded proteins from S. oleracea (Figure 3A) and B. 


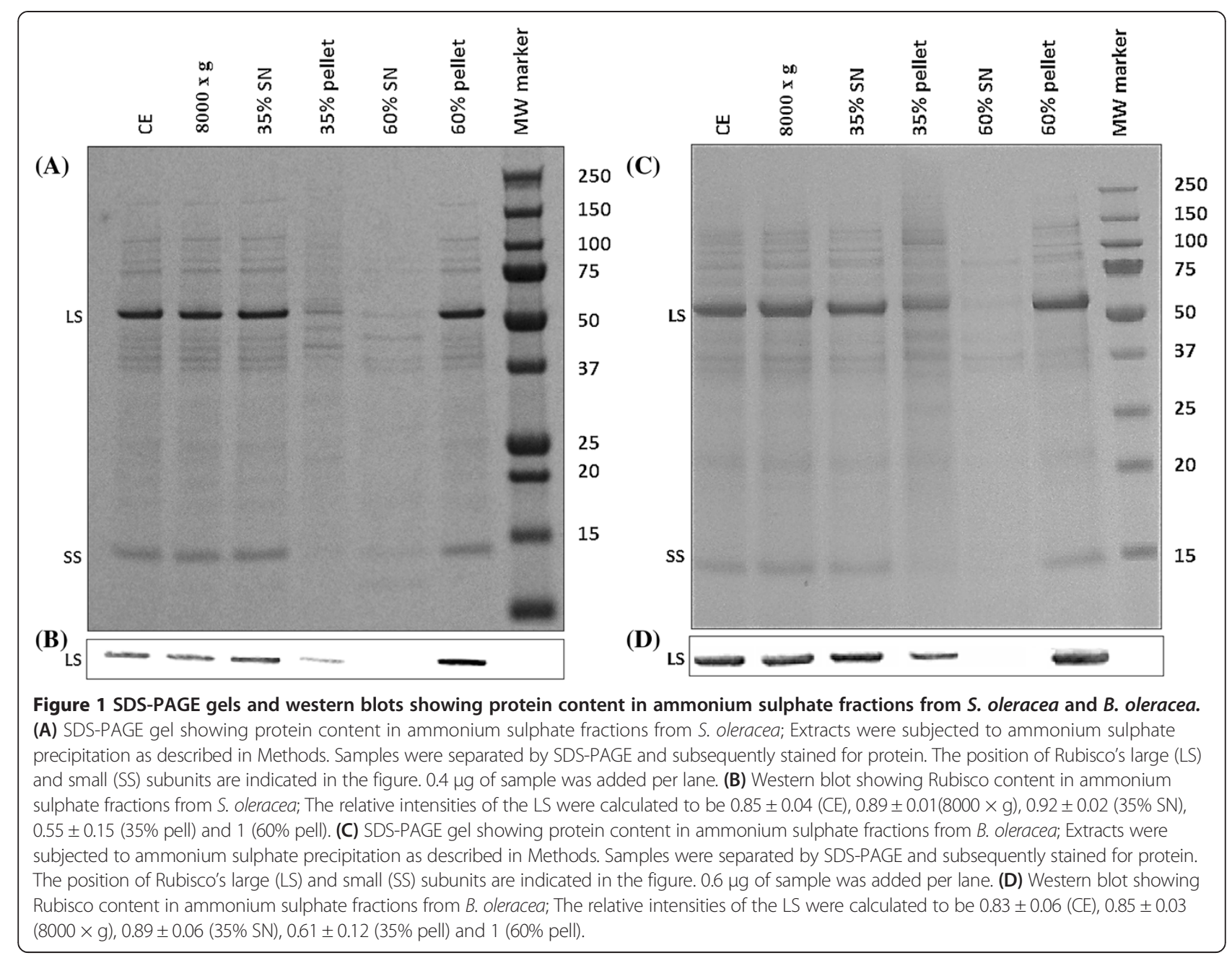

oleracea (Figure 4A), either did not bind to the column, or were eluted in the $1 \mathrm{M}\left(\mathrm{NH}_{4}\right)_{2} \mathrm{SO}_{4}$ wash step or in the $500 \mathrm{mM}$ step elution (see Additional file 1: Tables S1 and S2 for HIC purification tables). Interestingly there were five prominent peaks, observed at $500 \mathrm{mM}$, $400 \mathrm{mM}, 300 \mathrm{mM}, 200 \mathrm{mM}$ and $0 \mathrm{M}$ salt concentrations, all of which contained Rubisco (shown in the SDS-PAGE gel, Figures $3 \mathrm{~B}$ and $4 \mathrm{~B}$, and confirmed by the presence of the large subunit in the western blot, Figures $3 \mathrm{C}$ and $4 \mathrm{C}$ ), although it is of note that the $500 \mathrm{mM}$ fractions had relatively low purities of $65 \%$ ( $S$. oleracea) and $59 \%$ (B. oleracea) (calculated by analysis of SDS-PAGE gels, Figures $3 \mathrm{~B}$ and $4 \mathrm{~B}$ ). The UV trace of these step elution fractions revealed the presence of relatively broad peaks and tails, supporting the use of step elution. For each concentration of ammonium sulphate used in the step elution of protein in our HIC protocol, the column was allowed to equilibrate, such that the UV absorbance returned to the baseline. This ensured that all protein at the corresponding salt concentration had been eluted prior to proceeding with the next step elution.
The 0 M Rubisco fraction isolated from $S$. oleracea had a purity of $77 \%$, with the main impurities (as judged by densitometric scans of Coomassie stained gels, Figure 3B) being proteins with molecular weights of $\sim 45 \mathrm{kDa}$ and $\sim 26 \mathrm{kDa}$. In contrast, the $400 \mathrm{mM}$, $300 \mathrm{mM}$ and $200 \mathrm{mM}$ Rubisco fractions (isolated from S. oleracea) showed relatively high purities (between 90-93\%) with the main impurity present in all three fractions being a $\sim 41 \mathrm{kDa}$ protein. The $200 \mathrm{mM}$ fraction contained an additional $\sim 26 \mathrm{kDa}$ protein.

Interestingly, the HIC fractions obtained from B. oleracea extracts revealed some species-specific hydrophobic differences. While extracts from both species could be separated into fractions at $400 \mathrm{mM}, 300 \mathrm{mM}, 200 \mathrm{mM}$ and $0 \mathrm{M}$ salt concentrations, differences in the purity of these fractions were observed when compared with the results from $S$. oleracea. For example, the results from $B$. oleracea showed that the $300 \mathrm{mM}, 200 \mathrm{mM}$ and $0 \mathrm{mM}$ HIC fractions had high purity (93-96\%), with the $300 \mathrm{mM}$ fraction also containing a $\sim 39 \mathrm{kDa}$ protein impurity. Interestingly the fraction that eluted at $400 \mathrm{mM}$ salt showed a 
lower purity of $82 \%$ (Figure $4 \mathrm{~B}$ ), with the main impurities being due to $\sim 43 \mathrm{kDa}$ and $\sim 39 \mathrm{kDa}$ proteins. This is in contrast to the results from $S$. oleracea where we observed the $0 \mathrm{M}$ eluate to have a lower purity.

The protein impurities $(41 \mathrm{kDa}$ and $45 \mathrm{kDa}$ for S. oleracea) in these HIC fractions are of comparable molecular weight to the smaller and larger isoforms of Rubisco activase $[33,34]$, (a protein that has been indicated to associate with Rubisco [35]). Although there is no available data on the molecular weights of Rubisco activase isoforms from $B$. oleracea, it was speculated that the protein impurities $(39 \mathrm{kDa}$ and $43 \mathrm{kDa}$ ) in these HIC fractions could be due to the presence of the smaller and larger isoforms of Rubisco Activase. However, probing these fractions with antibodies against Rubisco activase did not support this notion in either species (data not shown).
Taken together, our data demonstrates the suitability of HIC as a method for obtaining high purity Rubisco. Rubisco extracted from the two species tested here $(S$. oleracea and $B$. oleracea) could be purified to similar levels to those reported using a rapid FPLC method, which obtained Rubisco from S. oleracea with 93\% purity [20]. It is worth noting that no significant degradation products of the large Rubisco subunit could be observed in the HIC fractions (Figures $3 \mathrm{C}$ and $4 \mathrm{C}$ ), indicating that Rubisco was not subject to proteolytic damage throughout the purification described here. This corroborates the protein integrity preserving character of the HIC method.

To ensure that the hydrophobically distinct populations of Rubisco were not a result of the use of $\left(\mathrm{NH}_{4}\right)_{2} \mathrm{SO}_{4}$ during the precipitation step or during $\mathrm{HIC}$, crude extracts from S. oleracea were loaded straight onto the HIC column 


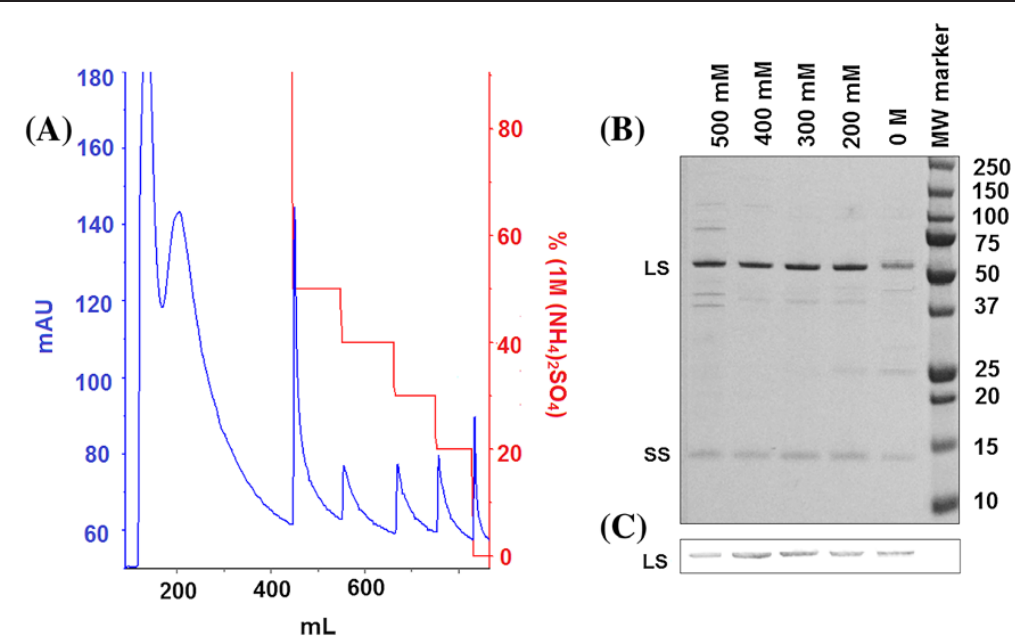

Figure 3 HIC elution profile from the $60 \%$ ammonium sulphate pellet isolated from S. oleracea, and the SDS-PAGE gel and western blot showing protein content from the elution steps of the HIC purification. (A) HIC elution profile generated by loading the $60 \%\left(\mathrm{NH}_{4}\right)_{2} \mathrm{SO}_{4}$ pellet isolated from S. oleracea; The ammonium sulphate pellet (60\% pell; see Figure 1) was loaded onto a $5 \mathrm{~mL}$ HiTrap HIC column, washed and eluted as described in Methods. The gradient used for the separation (red line) and the positions of the major absorption peaks obtained by measuring OD at $280 \mathrm{~nm}$ (blue line) following the HIC elution profile is shown. Elutions were performed at 500 mM, 400 mM, 300 mM, 200 mM, 0 M ammonium sulphate. (B) SDS-PAGE gel showing protein content from the different steps involved in the HIC purification protocol of Rubisco isolated from S. oleracea; Samples were separated by SDS-PAGE and subsequently stained for protein. The position of Rubisco's large (LS) and small (SS) subunits are indicated in the figure. $0.6 \mathrm{\mu g}$ of sample was added per lane. The purity of the Rubisco fractions were calculated as $65.2 \pm 4.7 \%(500 \mathrm{mM}), 91.9 \pm 3.1 \%,(400 \mathrm{mM}), 92.6 \pm 2.2 \%$, (300 mM), $90.2 \pm 2.4 \%$ (200 mM) and 76.6 $\pm 3.1 \%$ (0 M). (C) Western blot showing Rubisco content from HIC purified S. oleracea Rubisco fractions; The relative intensities of the LS for the four high purity Rubisco fractions were $0.97 \pm 0.03,(400 \mathrm{mM}), 0.98 \pm 0.02,(300 \mathrm{mM}), 0.94 \pm 0.04$ (200 mM) and 0.84 $\pm 0.06(0 \mathrm{M})$. The gels and western blot figures are representative of 3 sample sets.

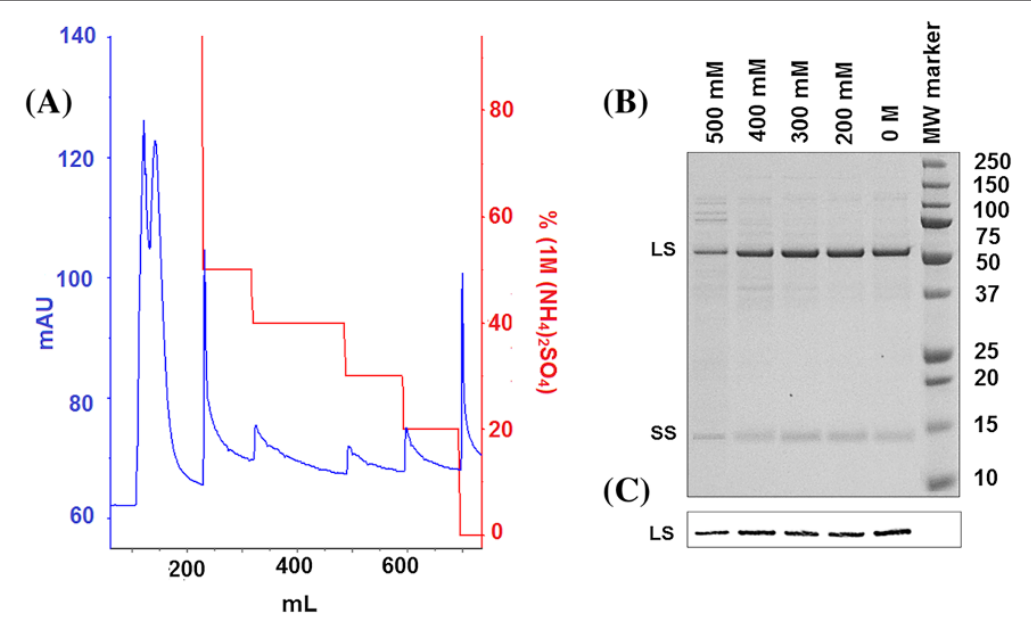

Figure 4 HIC elution profile from the $60 \%$ ammonium sulphate pellet isolated from $B$. oleracea, and the SDS-PAGE gel and western blot showing protein content from the elution steps of the HIC purification. (A) $\mathrm{HIC}$ elution profile generated by loading the $60 \%\left(\mathrm{NH}_{4}\right)_{2} \mathrm{SO}_{4}$ pellet isolated from B. oleracea; The ammonium sulphate pellet (60\% pellet; see Figure 1) was loaded onto a $5 \mathrm{~mL}$ HiTrap HIC column, washed and eluted as described in Methods. The gradient used for the separation (red line) and the positions of the major absorption peaks obtained by measuring OD at $280 \mathrm{~nm}$ (blue line) following the HIC elution profile is shown. Elutions were performed at $500 \mathrm{mM}, 400 \mathrm{mM}, 300 \mathrm{mM}, 200 \mathrm{mM}$, $0 \mathrm{M}$ ammonium sulphate. (B) SDS-PAGE gel showing protein content from the different steps involved in the HIC purification protocol of Rubisco isolated from B. oleracea; Samples were separated by SDS-PAGE and subsequently stained for protein. The position of Rubisco's large (LS) and small (SS) subunits are indicated in the figure. $0.6 \mu \mathrm{g}$ of sample was added per lane. The purity of the Rubisco fractions were calculated as $59.2 \pm 4.2 \%$ (500 mM), $82.3 \pm 6.0 \%$ (400 mM), $92.8 \pm 1.3 \%$ (300 mM), $96.1 \pm 0.2 \%$ (200 mM) and 95.2 $\pm 2.7 \%$ (0 M). (C) Western blot showing Rubisco content from HIC purified B. oleracea Rubisco fractions; The relative intensities of the LS for the four high purity Rubisco fractions were calculated as $0.76 \pm 0.11(400 \mathrm{mM}), 0.92 \pm 0.07(300 \mathrm{mM}), 0.98 \pm 0.02(200 \mathrm{mM})$ and $0.97 \pm 0.06(0 \mathrm{M})$. The gels and western blot figures are representative of 3 sample sets. 
(omitting the $\left(\mathrm{NH}_{4}\right)_{2} \mathrm{SO}_{4}$ precipitation step), followed by elution with potassium chloride $(\mathrm{KCl})$ instead of $\left(\mathrm{NH}_{4}\right)_{2} \mathrm{SO}_{4}$. We again observed hydrophobically distinct fractions of Rubisco under these conditions, using this $\mathrm{HIC}$ protocol, suggesting that the different fractions of Rubisco are not a result of the use of $\left(\mathrm{NH}_{4}\right)_{2} \mathrm{SO}_{4}$ (Additional file 2).

At this stage, we can only speculate as to why we observe hydrophobically distinct populations of Rubisco in both species. Separation by HIC clearly implies that the Rubisco populations differ in their hydrophobicity, at least on the surface of the protein. As Rubisco is a hugely complex enzyme, HIC could potentially be separating Rubisco populations where one or more of the enzyme's eight subunits might have undergone a conformational change, with the HIC fractions capturing the resulting populations generated through subunit heterogeneity. Alternatively, the difference in hydrophobicity could be due to protein - protein interactions (e.g. potentially with one of the impurities found in these fractions) or post-translational modifications. Furthermore, it is possible that the distinct Rubisco fractions are capturing diverse holoenzyme populations of Rubisco, with differing combinations of small subunits. As the small subunits provide structural stability [8], any difference in small subunit combinations could affect Rubisco's hydrophobic character. The distinct populations, and the protocol to obtain them, could therefore lead to exciting developments in understanding structural and interactome studies of this vital enzyme that will benefit current and future photosynthetic researchers.

\section{Kinetic analysis of the HIC fractions from S. oleracea and B. oleracea extracts}

The observed elution profiles from $S$. oleracea and $B$. oleracea extracts imply that there are differences in the hydrophobic character of Rubisco eluted in these different fractions. To probe whether the difference in the hydrophobic character could influence Rubisco's enzymological properties, we determined the $K_{M}$ and $K_{C A T}$ values for all Rubisco containing fractions. The Michaelis-Menten plot reveals that all the different fractions containing Rubisco, isolated using $\mathrm{HIC}$, from S. oleracea (Figure 5A) have similar enzymological properties. The Michaelis-Menten plot reveals that the enzymological properties of the $300 \mathrm{mM}, 200 \mathrm{mM}$ and $0 \mathrm{M} \mathrm{HIC}$ Rubisco containing fractions isolated from B. oleracea are also similar (Figure 6A). In contrast, the Rubisco activity in the $400 \mathrm{mM} \mathrm{HIC}$ fraction from $B$. oleracea extracts has a significant lower $\mathrm{K}_{\mathrm{CAT}}$ and a higher $\mathrm{K}_{\mathrm{M}}$ as compared to the $200 \mathrm{mM}$ and 0 M HIC fractions.

The $\mathrm{K}_{\mathrm{CAT}}$ and $\mathrm{K}_{\mathrm{M}}$ values for Rubisco from $S$. oleracea (see Table 1) are in reasonable agreement with previously published data [20,31]. As enzymological studies on Rubisco extracted from $B$. oleracea have not been previously published, we report here for the first time the $K_{\text {CAT }}$ for B. oleracea Rubisco (for the 300, 200 and $0 \mathrm{mM} \mathrm{HIC}$ fractions), and note that although a factor of 2 lower than $S$. oleracea, it is in reasonable agreement with values obtained from other C3 species (Table 1) [31]. The $K_{M}(\mathrm{RuBP})$ values (for the 300, 200 and $0 \mathrm{mM}$ HIC fractions) for $B$. oleracea (Table 1) are 2-3 times higher than that for $S$. oleracea, but are again in
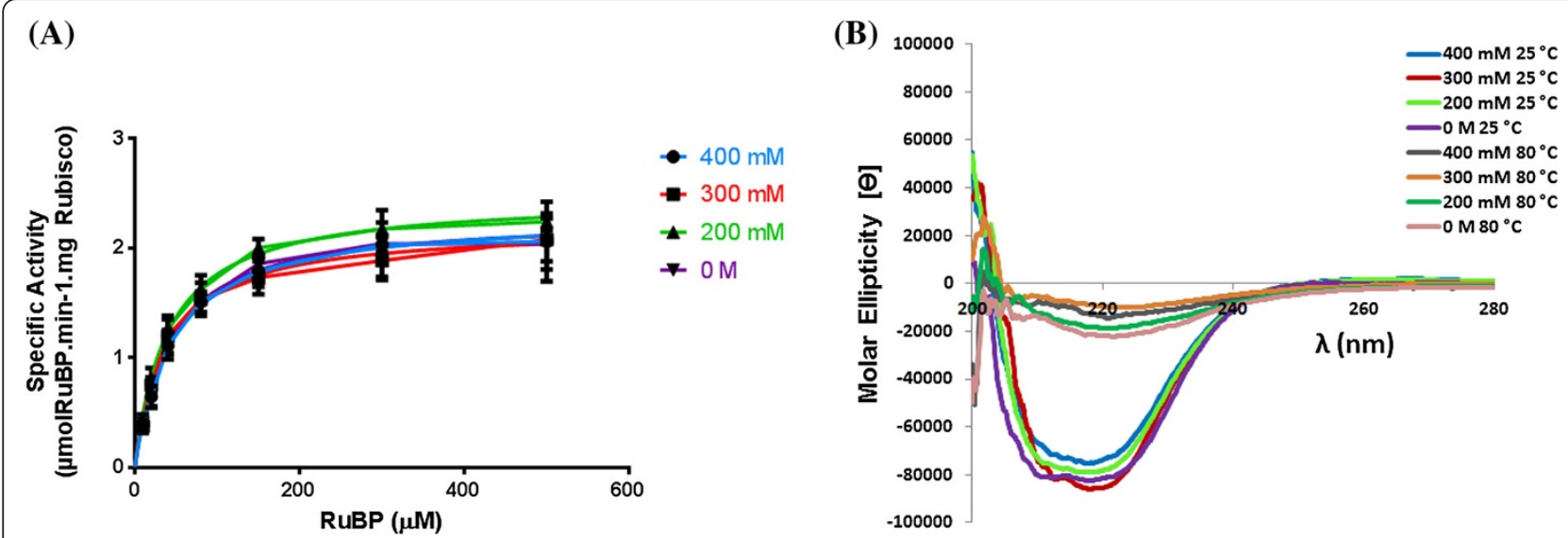

Figure 5 Kinetic and structural characterisation of four HIC purified Rubisco fractions isolated from B. oleracea extracts. (A)

Determination of the $K_{M}$ and $V_{\text {MAX }}$ values for the substrate RuBP for S. oleracea HIC purified fractions; Average $V_{M A x}$ values obtained for the 400, 300, 200 and $0 \mathrm{mM} \mathrm{HIC} \mathrm{fractions} \mathrm{were} 2.31 \pm 0.16,2.20 \pm 0.11,2.35 \pm 0.07$ and $2.23 \pm 0.07 \mu_{\text {mol.min }}^{-1}$. mgRubisco ${ }^{-1}$, respectively. Average $\mathrm{K}_{\mathrm{M}}$ values obtained were $44 \pm 11,39 \pm 7,39 \pm 4$ and $45 \pm 6 \mu \mathrm{M}$ respectively. Kinetic calculations and curve-fitting was done using GraphPad Prism 6 software. Error bars shown are standard deviation with $n=6$ (3 different biological replicates measured in duplicate). (B) Circular dichroism spectra of S. oleracea Rubisco fractions purified using $\mathrm{HIC}$; The $400 \mathrm{mM}, 300 \mathrm{mM}, 200 \mathrm{mM}$ and $0 \mathrm{M} \mathrm{HIC}$ fractions were was run at $25^{\circ} \mathrm{C}$ and then at $80^{\circ} \mathrm{C}$, at concentration between $0.15-0.25 \mathrm{mg} / \mathrm{mL}$. Data are shown as an average molar ellipticity [ $\theta$ ] of 3 biological repeats. 

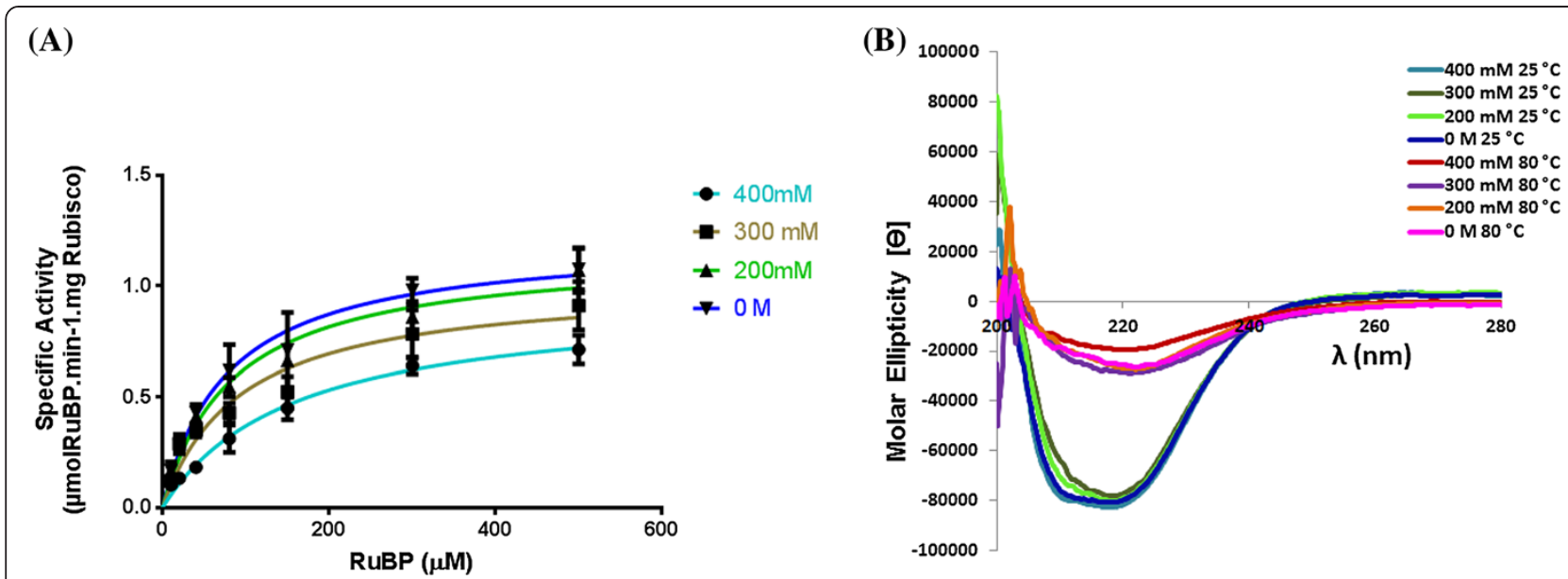

Figure 6 Kinetic and structural characterisation of four HIC purified Rubisco fractions isolated from S. oleracea extracts. (A)

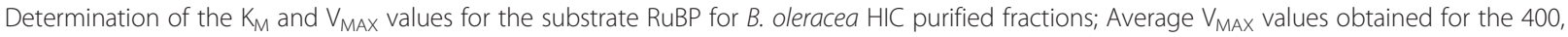
300,200 and $0 \mathrm{mM} \mathrm{HIC}$ fractions were $0.94 \pm 0.08,1.02 \pm 0.11,1.16 \pm 0.09$ and $1.21 \pm 0.10 \mu \mathrm{mol} \mathrm{min}^{-1}$. mgRubisco ${ }^{-1}$ respectively. Average $K_{M}$ values obtained were $147 \pm 35,92 \pm 29,83 \pm 19$ and $77 \pm 19 \mu \mathrm{M}$ respectively. Kinetic calculations and curve-fitting was done using GraphPad Prism 6 software. Error bars shown are standard deviation with $n=6$ (3 different biological replicates measured in duplicate). (B) Circular dichroism spectra of B. oleracea. Rubisco fractions purified using $\mathrm{HIC}$; The $400 \mathrm{mM}, 300 \mathrm{mM}, 200 \mathrm{mM}$ and 0 M Rubisco fractions were was run at $25^{\circ} \mathrm{C}$ and then at $80^{\circ} \mathrm{C}$, at concentration between $0.15-0.25 \mathrm{mg} / \mathrm{mL}$. Data are shown as an average molar ellipticity [ $\theta$ ] of 3 biological repeats.

reasonable agreement to $\mathrm{C} 3$ species reported by Yeoh et al. [36].

Since there is a significant difference in sequence homology between Rubisco from S. oleracea and B. oleracea (71.7\% for the small subunits of S. oleracea (RBCS2), and B. oleracea (BRA034024) and $91.4 \%$ for the large subunits), it is not unexpected that we should observe species specific differences in the HIC elution profiles and enzymological kinetics of Rubisco. However, the presence of distinct hydrophobic populations of Rubisco in both $S$. oleracea and B. oleracea suggests this phenomenon is not species specific.

An additional experiment was designed to investigate whether HIC could separate distinct subpopulations of Rubisco from Rubisco previously purified using IEC. Extracts from S. oleracea were purified by IEC and the Rubisco containing IEC fraction was then loaded onto an HIC column. Hydrophobically distinct fractions of Rubisco were again observed when eluted from the HIC column (Additional file 3). This further highlights the significance and potential use of this newly developed HIC protocol for Rubisco purification, and demonstrates the potential use of HIC in conjunction with the wellestablished IEC protocols.

\section{Circular dichroism studies reveal no significant structural differences in the Rubisco populations}

Circular dichroism (CD) can be a useful spectroscopic method to study conformational changes of proteins [37-39]. CD studies were carried out on the four HIC fractions derived from both $S$. oleracea and B. oleracea extracts, to probe the cause of the differences in the hydrophobicity of the samples (Figures $5 \mathrm{~B}$ and $6 \mathrm{~B}$ respectively). For comparison, an IEC fraction of the

Table 1 Summary of $V_{\text {MAX, }}, K_{\text {CAT }}$ and $K_{M}$ values of the HIC purified Rubisco fraction from S. oleracea and B. oleracea extracts

\begin{tabular}{|c|c|c|c|c|}
\hline Species & {$\left[\left(\mathrm{NH}_{4}\right)_{2} \mathrm{SO}_{4}\right] \mathrm{mM}$} & VMAX ( $\mu$ mol.min $^{-1} \cdot$ mgRubisco $\left.^{-1}\right)$ & $\mathrm{K}_{\mathrm{CAT}}^{*}\left(\mathrm{~s}^{-1}\right)$ & KM (RuBP) $(\mu \mathrm{M})$ \\
\hline \multirow[t]{4}{*}{ S. oleracea } & 400 & $2.31 \pm 0.16$ & $2.63 \pm 0.20$ & $44 \pm 11$ \\
\hline & 300 & $2.20 \pm 0.11$ & $2.52 \pm 0.14$ & $39 \pm 7$ \\
\hline & 200 & $2.35 \pm 0.07$ & $2.76 \pm 0.10$ & $39 \pm 4$ \\
\hline & 0 & $2.23 \pm 0.06$ & $2.59 \pm 0.08$ & $45 \pm 6$ \\
\hline \multirow[t]{4}{*}{ B. oleracea } & 400 & $0.94 \pm 0.08$ & $1.09 \pm 0.09$ & $147 \pm 35$ \\
\hline & 300 & $1.02 \pm 0.11$ & $1.17 \pm 0.13$ & $92 \pm 29$ \\
\hline & 200 & $1.16 \pm 0.09$ & $1.34 \pm 0.10$ & $83 \pm 19$ \\
\hline & 0 & $1.21 \pm 0.10$ & $1.39 \pm 0.11$ & $77 \pm 19$ \\
\hline
\end{tabular}

${ }^{*} \mathrm{~K}_{\text {CAT }}$ was calculated based on 8 active sites and a molecular weight of $550 \mathrm{~K} \mathrm{~g} / \mathrm{mol}$. 
corresponding extracts was also analysed (Additional file 4). Interestingly, each of the hydrophobically distinct fractions of Rubisco had similar values of molar ellipticites $[\theta]\left(\sim-8000 \mathrm{deg} \mathrm{cm}^{2} \mathrm{dmol}^{-1}\right)$ and structures of the $C D$ spectra when compared to each other, to the IEC fraction, and with CD spectra of Rubisco previously reported in the literature $[40,41]$. For comparison, maximum denaturation of the fractions was achieved by heating at $80^{\circ} \mathrm{C}$ (shown in Figures $5 \mathrm{~B}$ and $6 \mathrm{~B}$ ), which caused a large drop in the molar ellipticities of the samples $\left(\leq 2000 \mathrm{deg} \mathrm{cm}^{2} \mathrm{dmol}^{-1}\right)$, as well as a loss of structure in the spectra. This analysis demonstrates that there are no significant changes in the secondary structures of the Rubisco populations. Fractions purified using HIC or IEC showed similar CD spectra, suggesting that the Rubisco in the HIC fractions has the same structural integrity as the IEC purified Rubisco. With the latter being currently the standard method for obtaining pure Rubisco [20], the HIC method investigated here seems to produce pure Rubisco of comparable nature and quality. Furthermore, the $\mathrm{CD}$ experiments confirm that the heterogeneity of the Rubisco populations is not due to denaturation.

\section{Conclusions}

Taking these findings together, we can conclude that HIC is not only a valuable alternative purification method for form I Rubisco, but it also has the unique capability of being able to resolve distinct Rubisco populations. Since Rubisco isolated using HIC has similar values of purity and catalytic activity to that obtained using existing IEC purification methods, HIC has the potential to replace IEC, providing the additional benefit of avoiding high dilutions, dialysis and gel filtration chromatography. In addition, the ability to separate distinct Rubisco populations makes HIC a valuable method for current and future Rubisco researchers. This is of particular importance for investigators seeking to determine Rubisco's structure and interactome, since conformational alterations could significantly impact upon these results.

\section{Methods}

\section{Chemicals and equipment}

Chemicals for SDS-PAGE were obtained from Invitrogen. Instant Blue (Expedion) was used as a Coomassie staining agent. All other chemicals and enzymes were obtained from Sigma, except phosphoglycerate kinase (PGK) which was expressed and purified (see below). For homogenization of plant material, a Kenwood blender was used. Centrifugation was carried out in a Biofuge Primo R (Thermo Scientific). Purification was performed using an AKTA $^{\text {th }}$ design FPLC system. SDSPAGE gels and western blots were documented using a Fujifilm LAS-3000 Imaging System. The purity of the gels were determined using Image J software. Rubisco activity assays were performed in a Thermo Scientific Varioskan Flash Multimode reader.

\section{Extraction of Rubisco from leaves}

Unless stated otherwise, all procedures were performed rapidly at $4^{\circ} \mathrm{C}$ to maximize active enzyme recovery. The mid ribs of Spinach (S. oleracea) or Savoy Cabbage (B. oleracea) leaves were removed and the plant tissue was quickly frozen in liquid nitrogen and powdered in a mortar and pestle. $75 \mathrm{~mL}$ of extraction buffer $(20 \mathrm{mM}$ Hepes (pH 6.5) $5 \mathrm{mM} \mathrm{MgCl} 2,0.33 \mathrm{M}$ sorbitol, $0.2 \%$ (w/v) iso-ascorbic acid, $5 \mathrm{mM}$ DDT, $0.75 \mathrm{~mL}$ of plant protease inhibitor cocktail (Sigma)) was added to $15 \mathrm{~g}$ of plant tissue, and homogenization and cell lysis carried out in a blender using 20-30 pulses, of approximately $1-2$ second duration. The homogenate was filtered through two layers of Miracloth (Calbiochem) followed by centrifugation for $30 \mathrm{~min}$ at $3000 \times \mathrm{g}$ to remove intact cells and debris, and the cell extract $(\mathrm{CE})$ was further centrifuged for $10 \mathrm{~min}$ at $8000 \times$ g. The supernatant was subjected to $\left(\mathrm{NH}_{4}\right)_{2} \mathrm{SO}_{4}$ precipitation.

\section{Ammonium sulphate precipitation}

Two rounds of $\left(\mathrm{NH}_{4}\right)_{2} \mathrm{SO}_{4}$ precipitation were performed at 35 and $60 \%$ saturation. In each case, solid $\left(\mathrm{NH}_{4}\right)_{2} \mathrm{SO}_{4}$ was added to the desired percentage of saturation and the solution was stirred and left to equilibrate for $20 \mathrm{~min}$. The precipitate was collected by centrifugation for $10 \mathrm{~min}$ at $10000 \times \mathrm{g}$. The supernatant of the $35 \%$ saturation was subjected to the next round of precipitation. Protein pellets may be stored at $4^{\circ} \mathrm{C}$ for 2 days.

\section{Hydrophobic interaction chromatography using ammonium sulphate}

Purification was performed with a flow rate of $4 \mathrm{~mL} / \mathrm{min}$ using a $5 \mathrm{~mL}$ HiTrap $^{\text {ts }}$ Phenyl Sepharose 6 FF (high sub) column (GE Healthcare). Buffers were filtered before use through $0.45 \mu \mathrm{m}$ filters. $\left(\mathrm{NH}_{4}\right)_{2} \mathrm{SO}_{4}$ pellets were resuspended in HIC buffer (50 mM Tris- $\mathrm{HCl}(\mathrm{pH} 7.6, \mathrm{KOH})$, $20 \mathrm{mM} \mathrm{MgCl}_{2}, 20 \mathrm{mM} \mathrm{NaHCO} 3,0.2 \mathrm{mM}$ EDTA, $2 \mathrm{mM}$ DTT) containing $1 \mathrm{M}\left(\mathrm{NH}_{4}\right)_{2} \mathrm{SO}_{4}$, equilibrated and filtered through a $0.45 \mu \mathrm{m}$ filter to prevent clogging of the column. After washing the HIC column with $25 \mathrm{~mL}$ HIC buffer, the column was equilibrated with $25 \mathrm{~mL}$ HIC buffer (containing $1 \mathrm{M}\left(\mathrm{NH}_{4}\right)_{2} \mathrm{SO}_{4}$ ), and then the sample was loaded. After washing the column with HIC buffer (containing $\left.1 \mathrm{M}\left(\mathrm{NH}_{4}\right)_{2} \mathrm{SO}_{4}\right)$, a series of step elutions were performed at $\left(\mathrm{NH}_{4}\right)_{2} \mathrm{SO}_{4}$ concentrations of 500, 400, 300, 200 and $0 \mathrm{mM}$ (the column was washed between each elution step until the UV absorbance returned to baseline). Elution peaks were collected and desalted using $30 \mathrm{kDa}$ filter units (washed 4 times with $\mathrm{HIC}$ buffer at $5000 \times \mathrm{g}$ for $10 \mathrm{mins}$ ), and the subsequent 
samples were analysed by SDS-PAGE, Western blot, and for Rubisco activity (for protocols, see below). Protein concentrations were determined by Bradford assay [42].

\section{Hydrophobic interaction chromatography using potassium chloride}

Purification was performed with a flow rate of $4 \mathrm{~mL} / \mathrm{min}$ using a $5 \mathrm{~mL}$ HiTrap $^{\mathrm{Tm}}$ Phenyl Sepharose 6 FF (high sub) column (GE Healthcare). Buffers were filtered before use through $0.45 \mu \mathrm{m}$ filters. Crude extract samples were filtered through a $0.45 \mu \mathrm{m}$ filter to prevent clogging of the column. After washing the HIC column with $25 \mathrm{~mL}$ HIC buffer, the column was equilibrated with $25 \mathrm{~mL}$ $\mathrm{HIC}$ (containing $2 \mathrm{M} \mathrm{KCl}$ ), and then the sample was loaded. After washing the column with HIC buffer containing $2 \mathrm{M} \mathrm{KCl}$, a series of step elutions were performed at $\mathrm{KCl}$ concentrations of $1.5 \mathrm{M}, 1.0 \mathrm{M}, 0.6 \mathrm{M}$, $0.3 \mathrm{M}$ and $0 \mathrm{M}$ (the column was washed between each elution step until the UV absorbance returned to baseline). Elution peaks were collected and desalted using $30 \mathrm{kDa}$ filter units (washed 4 times with HIC buffer at $5000 \times$ g for 10 mins), and analysed for Rubisco activity. Protein concentrations were determined by Bradford assay.

\section{lon exchange chromatography followed by hydrophobic} interaction chromatography

Purification was performed with a flow rate of $3 \mathrm{~mL} / \mathrm{min}$ using $3 \times 5 \mathrm{~mL} \mathrm{HiTrap}{ }^{\mathrm{Tm}} \mathrm{Q}$ HP columns for increased yield (GE Healthcare). Buffers were filtered before use through $0.45 \mu \mathrm{m}$ filters. $\left(\mathrm{NH}_{4}\right)_{2} \mathrm{SO}_{4}$ pellets were resuspended in IEC buffer ( $25 \mathrm{mM}$ Tris- $\mathrm{HCl}(\mathrm{pH} 7.6, \mathrm{KOH})$, $10 \mathrm{mM} \mathrm{MgCl}_{2}, 10 \mathrm{mM} \mathrm{NaHCO}, 0.1 \mathrm{mM}$ EDTA, $2 \mathrm{mM}$ DTT) and filtered through a $0.45 \mu \mathrm{m}$ filter to prevent clogging of the column. After washing the IEC column with $25 \mathrm{~mL}$ IEC buffer containing $1 \mathrm{M} \mathrm{KCl}$, the column was equilibrated with $25 \mathrm{~mL}$ of IEC buffer, and then the sample was loaded. After washing the column with IEC buffer, the sample was eluted over a linear gradient from 0 to $0.5 \mathrm{M} \mathrm{KCl}$, over a 90 minute period. Rubisco is known to elute between $\sim 0.30-0.35 \mathrm{M} \mathrm{KCl}$.

The Rubisco peak was collected and desalted using $30 \mathrm{kDa}$ filter units (washed 4 times with HIC buffer at $5000 \times \mathrm{g}$ for $10 \mathrm{mins}$ ), and analysed for Rubisco activity. The remaining sample was made up to $1 \mathrm{M}\left(\mathrm{NH}_{4}\right)_{2} \mathrm{SO}_{4}$ in HIC buffer, and filtered through a $0.45 \mu \mathrm{m}$ filter. After washing the HIC column (5 mL HiTrap ${ }^{\text {тm }}$ Phenyl Sepharose 6 FF (high sub)) with $25 \mathrm{~mL} \mathrm{HIC} \mathrm{buffer,} \mathrm{the} \mathrm{col-}$ umn was equilibrated with $25 \mathrm{~mL} \mathrm{HIC} \mathrm{(containing} 1 \mathrm{M}$ $\left.\left(\mathrm{NH}_{4}\right)_{2} \mathrm{SO}_{4}\right)$, and then the sample was loaded. After washing with $\mathrm{HIC}$ buffer containing $1 \mathrm{M}\left(\mathrm{NH}_{4}\right)_{2} \mathrm{SO}_{4}$, a series of step elutions were performed at $\left(\mathrm{NH}_{4}\right)_{2} \mathrm{SO}_{4}$ concentrations of 500, 400, 300, 200 and $0 \mathrm{mM}$ (the column was washed between each elution step until the UV absorbance returned to baseline). Elution peaks were collected and desalted using $30 \mathrm{kDa}$ filter units (washed 4 times with HIC buffer at $5000 \times \mathrm{g}$ for 10 mins), and analysed for Rubisco activity. Protein concentrations were determined by Bradford assay.

\section{SDS polyacrylamide gel electrophoresis (SDS-PAGE)}

SDS-PAGE was performed in NuPage ${ }^{\oplus}$ Bis-Tris 4-12\% gradient gels (Invitrogen) according to the manufacturer's protocol [43]. Staining was carried with InstantBlue Coomassie stain.

\section{Western blot}

After SDS-PAGE, the gel was equilibrated in $4^{\circ} \mathrm{C}$ Transfer buffer (Tris $25 \mathrm{mM}$, Glycine $192 \mathrm{mM}$, Methanol reagent grade $20 \%(\mathrm{v} / \mathrm{v}))$ for 15 mins. Immunoblotting using a Criterion $^{\text {TM }}$ Blotter Cell (Bio-rad) was carried out at $70 \mathrm{~V}$ for 90 minutes using a Bio-rad Powerpac ${ }^{\circledR}$ 1000. After blotting, the nitrocellulose membrane was washed twice in TBST, pH 7.5 (Tris $50 \mathrm{mM}, \mathrm{NaCl} 150 \mathrm{mM}$, Tween $20,0.05 \%(\mathrm{v} / \mathrm{v}))$ at room temperature on an orbital shaker, and followed by washing with Blocking solution (2\% (w/v) milk powder dissolved in TBST) for 2 hours at room temperature. The membrane was incubated with primary Antibody Solution (rabbit anti-RbcL (Agrisera) dissolved in 0.5\% Blocking Solution at 1:5000) overnight at $4^{\circ} \mathrm{C}$, followed by 5 washes with TBST, for 3 minutes each. The membrane was incubated with secondary Antibody Solution (donkey anti-rabbit IgG (H\&L) HRP conjugated (Agrisera) dissolved in 0.5\% Blocking Solution at 1:10000) for 2 hours, after which, the membrane was washed 3 times at 10 minute intervals with TBST. Lumi-Light substrate (Roche) was mixed with the membrane for 5 minutes and then the membrane was quickly imaged.

\section{Rubisco activity assay}

Rubisco carboxylase activity was determined using a nonradioactive microplate-based assay, which determines the product [(3-phosphoglycerate (3-PGA)] in an enzymic cycle between glycerol-3-phospahte dehydrogenase and glycerol-3-phospate oxidase, adapted from Sulpice et al. [44]. The assay was monitored through the oxidation of NADH by optical density measurements at $340 \mathrm{~nm}$ at $25^{\circ} \mathrm{C}$. $15 \mu \mathrm{L}$ of Rubisco was added to the initial buffer for activation (containing $100 \mathrm{mM}$ Tricine $(\mathrm{pH}$ 8.0, $\mathrm{KOH}), 20 \mathrm{mM} \mathrm{MgCl} 2,2 \mathrm{mM}$ EDTA and $10 \mathrm{mM}$ $\mathrm{NaHCO}_{3}$ ), to give a total volume of $30 \mu \mathrm{L}$. The concentration of $\mathrm{NaHCO}_{3}$ was confirmed to be saturating. While incubating the sample for 15 mins at room temperature, $15 \mathrm{uL}$ of different concentrations of RuBP (giving final concentrations of $10 \mu \mathrm{M}$ to $500 \mu \mathrm{M}$ ) was pipetted into a 96 well plate. The Rubisco/initial buffer mixture was then added to the wells (giving a total volume of $45 \mu \mathrm{L}$ ) and allowed to react for 60 seconds, after 
which, $15 \mu \mathrm{L}$ of absolute ethanol was added to stop the reaction. To minimise the amount of assay enzymes used, $20 \mu \mathrm{L}$ of the assay mixture was added to a 384 well plate (after 5 mins of reaction with ethanol), and $20 \mu \mathrm{L}$ of determination buffer was added to start the reaction [final concentrations in $40 \mu \mathrm{L}$ were: $1.875 \mathrm{u} / \mathrm{mL}$ phosphoglycerate kinase (PGK), $3 \mathrm{u} / \mathrm{mL}$ glyceraldehyde3-phosphate dehydrogenase (GAPDH), $2.5 \mathrm{u} / \mathrm{mL} \alpha$ glycerol-3-phosphate dehydrogenase-/triose-P isomerase (G3PDH-TPI), $100 \mathrm{u} / \mathrm{mL}$ glycerol-3-phosphate oxidase (G3P-OX), $700 \mathrm{u} / \mathrm{mL}$ catalase, $3 \mathrm{mM}$ ATP, $0.5 \mathrm{mM}$ $\mathrm{NADH}, 1 \mathrm{mM} \mathrm{MgCl}$, $60 \mathrm{mM}$ Tricine (pH 8.0, KOH)]. The rates of reaction were calculated as the decrease of the absorbance in OD. $\mathrm{min}^{-1}$ and converted to $\mu \mathrm{mol}$ by use of a 3-phosphoglyceric acid (3PGA) calibration curve.

\section{Expression and purification of phosphoglycerate kinase}

The coding region of the DNA sequence of phosphoglycerate kinase 1 (Saccharomyces cerevisiae) was cloned into pGEX-6P-1 expression vector (GE Healthcare). Phosphoglycerate kinase 1 expression and purification was performed as previously described [45].

\section{Circular dichroism}

CD spectra were measured using a JASCO-715 Circular Dichroism Spectropolarimeter, with the use of using JASCO PTS-604 T Temperature Controller, to regulate the temperature. Samples were allowed to incubate at $25^{\circ} \mathrm{C}$ and $80^{\circ} \mathrm{C}$ for 10 minutes before $\mathrm{CD}$ measurements were taken. Molecular ellipticities [ $\theta]$ are reported, using an average molecular weight of $560 \mathrm{KDa}$ for Rubisco, and a path length of $0.1 \mathrm{~cm}$. Sample were prepared in HIC buffer at protein concentrations between 0.15$0.25 \mathrm{mg} / \mathrm{mL}$.

\section{Additional files}

Additional file 1: Purification tables for S. oleracea (Table S1) and $B$. oleracea (Table S2). NB. * not calculated for these samples. ${ }^{-}$Activity was too low to measure. ${ }^{a}$ Calculations based on 'cell extract'.

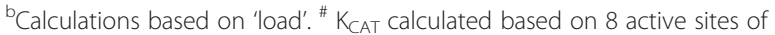
Rubisco, with a total molecular weight of $550 \mathrm{~K} \mathrm{~g} / \mathrm{mol}$.

Additional file 2: HIC elution profile (using potassium chloride $(\mathrm{KCl}))$ from cell extract of S. oleracea; and the SDS-PAGE gel showing protein content from the different elution steps of the HIC purification protocol. (A) HIC (using potassium chloride (KCl)) elution profile generated by loading cell extract isolated from S. oleracea; The cell extract was loaded at $2 \mathrm{M} \mathrm{KCl}$ onto a $5 \mathrm{~mL}$ HiTrap HIC column, washed and eluted as described in Methods. The gradient used for the separation (red line) and the positions of the major absorption peaks obtained by measuring OD at $280 \mathrm{~nm}$ (blue line) following the HIC elution profile is shown. Elutions were performed at $1.5 \mathrm{M}, 1.0 \mathrm{M}, 0.6 \mathrm{M}$, $0.3 \mathrm{M}$ and $0 \mathrm{M} \mathrm{KCl}$. (B) SDS-PAGE gel showing protein content from the different steps involved in the HIC potassium chloride purification protocol of Rubisco isolated from S. oleracea; Samples were separated by SDS-PAGE and subsequently stained for protein. The position of Rubisco's large (LS) and small (SS) subunits are indicated in the figure. $0.4 \mu \mathrm{g}$ of sample was added per lane. The purity of the CE sample was calculated as $68.2 \pm 3.1 \%$, and HIC fraction containing Rubisco had purities of $86.4 \pm 1.4(1.5 \mathrm{M}), 87.7 \pm$ $2.1 \%(1.0 \mathrm{M}), 89.1 \pm 1.7 \%(0.6 \mathrm{M}), 81.3 \pm 3.0 \%(0.3 \mathrm{M})$ and $70.1 \pm 4.2 \%(0 \mathrm{M})$. The gels are representative of 2 sample sets.

Additional file 3: Kinetic characterisation of the IEC and HIC purified Rubisco fractions from S. oleracea extracts. Determination of the $K_{M}$ and $V_{\text {MAX }}$ values for the substrate RuBP for $S$. oleracea Rubisco purified using IEC and followed by further purification of the IEC fraction using HIC; Rubisco was purified using IEC, and the subsequent fraction was then loaded onto an $\mathrm{HIC}$ column at $1 \mathrm{M}\left(\mathrm{NH}_{4}\right)_{2} \mathrm{SO}_{4}$, and eluted at $\left(\mathrm{NH}_{4}\right)_{2} \mathrm{SO}_{4}$ concentrations of $500 \mathrm{mM}, 400 \mathrm{mM}, 300 \mathrm{mM}, 200 \mathrm{mM}$ and $0 \mathrm{M}$, as per Methods section. Average $V_{\text {MAX }}$ and $K_{M}$ values obtained for the IEC fraction was $2.8 \pm 0.22 \mu \mathrm{mol}$.min.mg and $47 \pm 13 \mu \mathrm{M}$. Average $V_{\text {MAX }}$ values obtained for, $300 \mathrm{mM}, 200 \mathrm{mM}$ and $0 \mathrm{M}$ was $3.0 \pm 0.16,3.1 \pm$ 0.10 and $2.8 \pm 0.13 \mu \mathrm{mol}$.min.mg respectively. Average $K_{M}$ values obtained were $46 \pm 8,40 \pm 5$ and $47 \pm 8 \mu \mathrm{M}$ respectively. It is of note that although there was a peak in the UV trace of the elution profile at $400 \mathrm{mM}\left(\mathrm{NH}_{4}\right)_{2} \mathrm{SO}_{4}$ elution, there was not enough protein obtained to perform kinetic analysis, as the peak was very small (even when more protein was loaded). Kinetic calculations and curve-fitting was done using GraphPad Prism 6 software. Error bars shown are standard deviation with $\mathrm{n}=6$ (3 different biological replicates measured in duplicate).

Additional file 4: Circular dichroism spectra of S. oleracea Rubisco, purified using IEC. Rubisco purified using IEC was run at $25^{\circ} \mathrm{C}$ at a concentration of $0.2 \mathrm{mg} / \mathrm{mL}$. Data are shown as an average molar ellipticity $[\theta]$ of 3 biological repeats.

\section{Abbreviations}

HIC: Hydrophobic interaction chromatography; IEC: lon exchange chromatography; RuBP: Ribulose-1,5-bisphophate; RLPs: Rubisco like proteins; CA1P: 2 carboxy-D-arabinitol 1-phosphate; SDS-PAGE: Sodium dodecyl sulphate polyacrylamide gel electrophoresis; CD: Circular dichroism; PGK: Phosphoglycerate kinase; CE: Cell extract; 3PGA: 3-phosphoglyceric acid; GAPDH: Glyceraldehyde-3-phosphate dehydrogenase; G3PDH-TPI: $\mathrm{mL}$ a-glycerol-3-phosphate dehydrogenase-/triose-P isomerase; G3POX: Glycerol-3-phosphate oxidase; IPTG: Isopropyl $\beta$-D-1-thiogalactopyranoside; GST: Glutathione S-transferase.

\section{Competing interests}

The authors declare that they have no competing interests.

\section{Authors' contributions}

KOD carried out the purification study, enzymological studies, and CD analysis. PP and ZG assisted in the purification and enzymological studies. MSD and SK carried out preliminary purification studies with B. oleracea. LHM expressed and purified phosphoglycerate kinase. RW and LB conceived the study and participated in its design. KOD, RW and LB coordinated and drafted the manuscript. All authors read and approved the final manuscript.

\section{Acknowledgements}

This work was supported by a Royal Society University Fellowship to LB, an EPSRC Centre for Doctoral Training Studentship from the Institute of Chemical Biology (Imperial College London) awarded to KOD.

\section{Author details}

${ }^{1}$ Institute of Chemical Biology, Department of Chemistry, Imperial College, Flowers Building, South Kensington Campus, Exhibition Road, London SW7 2AZ, UK. ${ }^{2}$ Department of Chemistry, Imperial College, South Kensington Campus, Exhibition Road, London SW7 2AZ, UK.

Received: 10 January 2014 Accepted: 28 May 2014 Published: 12 June 2014

\section{References}

1. Spreitzer R, Salvucci M: Rubisco: structure, regulatory interactions, and possibilities for a better enzyme. Annu Rev Plant Biol 2002, 53:449-475.

2. Andersson I: Catalysis and regulation in Rubisco. J Exp Bot 2008, 59(7):1555-1568

3. Behrenfield MJ, Randerson JT, Falkowski P: Primary Production of the Biosphere: Integrating Terrestrial and Oceanic Components. Science 1998, 281(5374):237-240. 
4. Ellis RJ: Biochemistry: Tackling unintelligent design. Nature 2010, 463(7278):164-165.

5. Sage RF, Sage TL, Kocacinar F: Photorespiration and the evolution of C4 photosynthesis. Annu Rev Plant Biol 2012, 63:19-47.

6. Zhu XG, Portis AR, Long SP: Would transformation of C3 crop plants with foreign Rubisco increase productivity? A computational analysis extrapolating from kinetic properties to canopy photosynthesis. Plant Cell Environ 2004, 27(2):155-165.

7. Ellis JR: The most abundant protein in the world. Trends Biochem Sci 1979, 4(11):241-244.

8. Andersson I, Backlund A: Structure and function of Rubisco. Plant Physiol Biochem 2008, 46(3):275-291.

9. Tabita FR, Satagopan S, Hanson T, Kreel N, Scott S: Distinct form I, II, III, and IV Rubisco proteins from the three kingdoms of life provide clues about Rubisco evolution and structure/function relationships. J Exp Bot 2008 59(7):1515-1524

10. Chapman MS, Cascio D, Eisenberg D, Suh SW, Smith WW: Sliding-layer conformational change limited by the quaternary structure of plant RuBisCO. Nature 1987, 329(6137):354-356.

11. Andersson I, Knight S, Schneider G, Lindqvist Y, Lundqvist T: Crystalstructure of the active-site of Ribulose-Bisphosphate Carboxylase. Nature 1989, 337(6204):229-234.

12. Andersson I, Taylor TC: Structural framework for catalysis and regulation in ribulose-1,5-bisphosphate carboxylase/oxygenase. Arch Biochem Biophys 2003, 414(2):130-140.

13. Andrews TJ: Catalysis by cyanobacterial ribulose-bisphosphate carboxylase large subunits in the complete absence of small subunits. J Biol Chem 1988, 263(25):12213-12219.

14. Lee B, Tabita FR: Purification of recombinant ribulose-1,5-bisphosphate carboxylase/oxygenase large subunits suitable for reconstitution and assembly of active L8S8 enzyme. Biochemistry 1990, 29(40):9352-9357.

15. Whitney SM, Sharwood RE, Orr D, White SJ, Alonso H, Galmés J: Isoleucine 309 acts as a C4 catalytic switch that increases ribulose-1,5-bisphosphate carboxylase/oxygenase (rubisco) carboxylation rate in Flaveria. Proc Natl Acad Sci 2011, 108(35):14688-14693.

16. Ishikawa C, Hatanaka T, Misoo S, Miyake C, Fukayama H: Functional Incorporation of Sorghum Small Subunit Increases the Catalytic Turnover Rate of Rubisco in Transgenic Rice. Plant Physiol 2011, 156(3):1603-1611.

17. Spreitzer R: Role of the small subunit in ribulose-1,5-bisphosphate carboxylase/oxygenase. Arch Biochem Biophys 2003, 414(2):141-149.

18. Uemura K, Anwaruzzaman, Miyachi S, Yokota A: Ribulose-1,5-bisphosphate carboxylase/oxygenase from thermophilic red algae with a strong specificity for CO2 fixation. Biochem Biophys Res Commun 1997, 233(2):568-71

19. Suarez R, Miro M, Cerda V, Perdomo JA, Galmes J: Automated flow-based anion-exchange method for high-throughput isolation and real-time monitoring of RuBisCO in plant extracts. Talanta 2011, 84(5):1259-66.

20. Salvucci ME, Portis AR Jr, Ogren WL: Purification of ribulose-1,5-bisphosphate carboxylase/oxygenase with high specific activity by fast protein liquid chromatography. Anal Biochem 1986, 153(1):97-101.

21. Jakob R: 2 Quick methods for isolation of Ribulose-1,5-Bisphosphate Carboxylase Oxygenase. Prep Biochem 1988, 18(3):351-360.

22. Whitney SM, Sharwood RE: Linked Rubisco subunits can assemble into functional oligomers without impeding catalytic performance. J Biol Chem 2007, 282(6):3809-18.

23. Hemmingsen SM, Ellis RJ: Purification and properties of ribulosebisphosphate carboxylase large subunit binding protein. Plant Physiol 1986, 80(1):269-76.

24. Carmo-Silva AE, Barta C, Salvucci ME: Isolation of ribulose-1,5-bisphosphate carboxylase/oxygenase from leaves. Methods in molecular biology (Clifton, NJ) 2011, 684:339-47.

25. Whitney SM, Kane HJ, Houtz RL, Sharwood RE: Rubisco oligomers composed of linked small and large subunits assemble in tobacco plastids and have higher affinities for CO2 and O2. Plant Physiol 2009, 149(4):1887-95.

26. Rosichan JL, Huffaker RC: Source of Endoproteolytic activity associated with purified Ribulose Bisphosphate Carboxylase. Plant Physiol 1984, 75(1):74-77

27. Kreel NE, Tabita FR: Substitutions at Methionine 295 of Archaeoglobus fulgidus Ribulose-1,5-bisphosphate Carboxylase/Oxygenase Affect Oxygen Binding and CO2/O2 Specificity. J Biol Chem 2007, 282(2):1341-1351.
28. McCurry SD, Gee R, Tolbert NE: Ribulose-1,5-bisphosphate carboxylase/ oxygenase from spinach, tomato, or tobacco leaves. Methods Enzymol 1982, 90 Pt E(Pt E):515-21.

29. Parry MAJ, Andralojc PJ, Parmar S, Keys AJ, Habash D, Paul MJ, Alred R, Quick WP, Servaites JC: Regulation of Rubisco by inhibitors in the light. Plant Cell and Environment 1997, 20(4):528-534

30. Parry MAJ, Keys AJ, Madgwick PJ, Carmo-Silva AE, Andralojc PJ: Rubisco regulation: a role for inhibitors. J Exp Bot 2008, 59(7):1569-1580.

31. Sage RF: Variation in the k(cat) of Rubisco in C(3) and C(4) plants and some implications for photosynthetic performance at high and low temperature. J Exp Bot 2002, 53(369):609-20.

32. Uemura K, Suzuki Y, Shikanai T, Wadano A, Jensen RG, Chmara W, Yokota A: A Rapid and Sensitive Method for Determination of Relative Specificity of RuBisCO from Various Species by Anion-Exchange Chromatography. Plant Cell Physiol 1996, 37(3):325-331.

33. Shen JB, Ogren WL: Alteration of spinach ribulose-1,5-bisphosphate carboxylase/oxygenase activase activities by site-directed mutagenesis. Plant Physiol 1992, 99(3):1201-7

34. Shen JB, Orozco EM Jr, Ogren WL: Expression of the two isoforms of spinach ribulose 1,5-bisphosphate carboxylase activase and essentiality of the conserved lysine in the consensus nucleotide-binding domain. J Biol Chem 1991, 266(14):8963-8.

35. Portis AR Jr: Rubisco activase - Rubisco's catalytic chaperone. Photosynth Res 2003, 75(1):11-27.

36. Yeoh $\mathrm{H}-\mathrm{H}$, Badger MR, Watson L: Variations in Kinetic Properties of Ribulose-1,5-bisphosphate Carboxylases among Plants. Plant Physio/ 1981, 67(6):1151-1155

37. Kelly SM, Price NC: The application of circular dichroism to studies of protein folding and unfolding. Biochim Biophys Acta 1997, 1338(2):161-85

38. Kelly SM, Jess TJ, Price NC: How to study proteins by circular dichroism. Biochim Biophys Acta 2005, 1751(2):119-39.

39. Greenfield NJ: Applications of circular dichroism in protein and peptide analysis. TrAC Trends Anal Chem 1999, 18(4):236-244.

40. Voordouw G, van der Vies SM, Bouwmeister PP: Dissociation of ribulose1,5-bisphosphate carboxylase/oxygenase from spinach by urea. Eur J Biochem 1984, 141(2):313-8.

41. Li G, Mao H, Ruan X, Xu Q, Gong Y, Zang X, Zhao N: Association of heatinduced conformational change with activity loss of Rubisco. Biochem Biophys Res Commun 2002, 290(3):1128-32.

42. Bradford MM: A rapid and sensitive method for the quantitation of microgram quantities of protein utilizing the principle of protein-dye binding. Anal Biochem 1976, 72:248-54.

43. Laemmli UK: Cleavage of structural proteins during the assembly of the head of bacteriophage T4. Nature 1970, 227(5259):680-5.

44. Sulpice R, Tschoep H, Von Korff M, Büssis D, Usadel B, Höhne M, WituckaWall H, Altmann T, Stitt M, Gibon Y: Description and applications of a rapid and sensitive non-radioactive microplate-based assay for maximum and initial activity of D-ribulose-1,5-bisphosphate carboxylase/oxygenase. Plant Cell Environ 2007, 30(9):1163-1175.

45. Mak L, Vilar R, Woscholski R: Characterisation of the PTEN inhibitor VO-OHpic. J Chem Biol 2010, 3(4):157-163.

\section{doi:10.1186/1746-4811-10-17}

Cite this article as: O'Donnelly et al:: Isolation and kinetic

characterisation of hydrophobically distinct populations of form I Rubisco. Plant Methods 2014 10:17. 